\title{
The Biology and Clinical Relevance of Sentinel Lymph Nodes in Melanoma
}

\author{
Brian Parrett, Lilly Fadaki, Jennifer Y. Rhee and Stanley P.L. Leong \\ Center for Melanoma Research \& Treatment and Department of Surgery \\ California Pacific Medical Center and Research Institute \\ San Franciso, CA, \\ USA
}

\section{Introduction}

The initial route of metastases in most patients with melanoma is through lymphatics to the regional nodes (Morton et al., 1992) [Fig.1]. However, routine lymphadenectomy for patients with early stage melanoma is unwarranted because most of these patients $(\sim 80 \%)$ do not have nodal metastases, are unlikely to benefit from the operation, and may suffer complications including lymphedema, seroma, infection and wound breakdown. However, a significant portion of patients with melanoma, predicted by primary tumor factors, harbor clinically undetectable regionally lymph node metastases at time of presentation. Delay of elective lymph node dissection until the presence of palpable nodes may allow the spread of melanoma to other nodes and distant sites with a decrease in long-term survival (Morton et al., 2006). The key to solving this clinical dilemma is to provide a minimally invasive method to selecting the relevant "sentinel lymph node" (SLN) in a specific basin to determine nodal micrometastasis (Morton et al., 1992). The SLN is accordingly the first lymph node(s) receiving direct afferent drainage from the primary tumor and thus is most likely to contain metastatic disease if any regional lymph nodes are involved. The technique of SLN biopsy is best named selective sentinel lymph node dissection (SLND) and allows surgeons to determine the spread of melanoma through lymphatic channels from the primary tumor; it has substantially impacted the way cutaneous melanoma is staged and managed.

The relatively orderly fashion of melanoma metastasis from the primary site to the SLNs and then to the non-SLNs prior to systemic sites is supportive of the spectrum theory of cancer spread (Hellman, 1994; Leong, 2004) [Fig. 1]. This theory states that for a given malignant lesion, development of nodal and systemic metastasis from localized disease is a genetically driven process of progression within the tumor microenvironment to distant body sites, most often through the "gateway" of the SLN(s). Selective SLND is an ideal procedure because it is minimally invasive, yet powerful enough to select the relevant lymph node of the nodal basin, without a complete node dissection. It is now widely accepted that the SLN status is the most important factor in predicting outcomes and determining further treatment for melanoma and this is the focus of the chapter (Leong, 2004). 


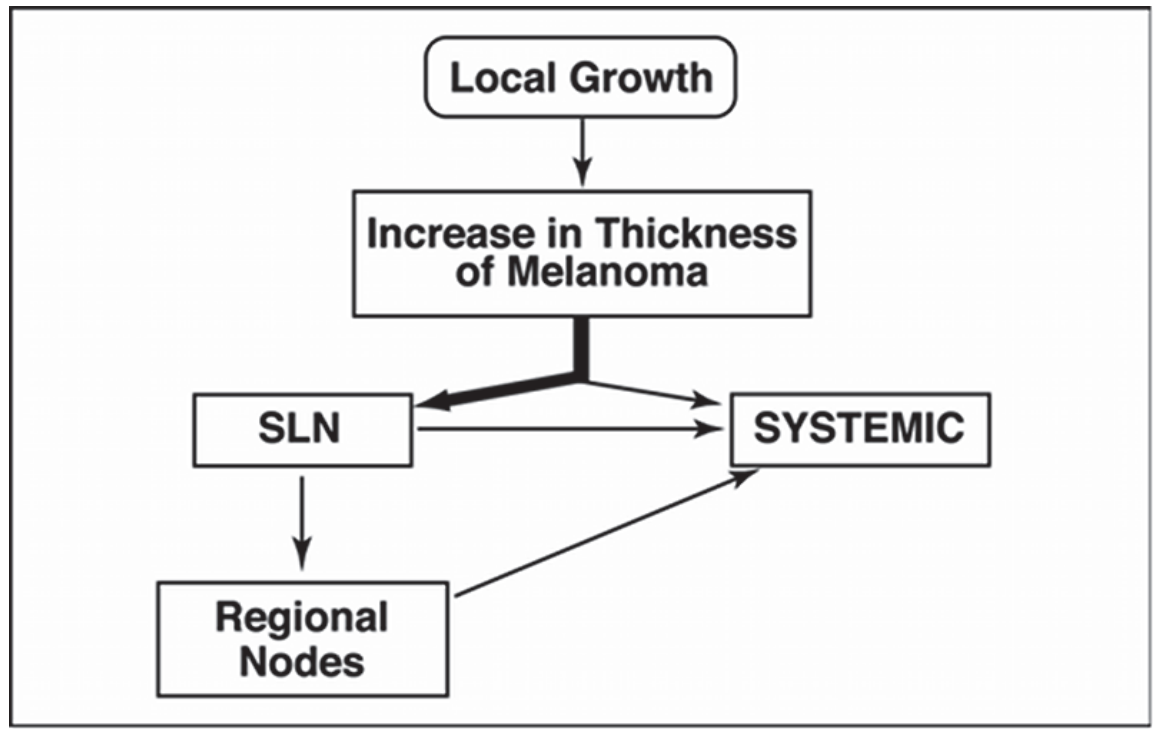

Fig. 1. The figure depicts progression of melanoma from the primary site to the SLN, then to non-SLN or regional nodes and distant sites. Occasionally, cancer cells may bypass the lymph nodes and spread to distant sites through vascular channels. In the majority of the cases (approximately 80\%), the SLN is the gateway for cancer spread (bold arrow pathway in figure).

\section{The sentinel lymph node in melanoma}

\subsection{History and rationale}

In 1977, Cabanas described an approach to staging penile carcinoma after using lymphangiograms in patients to determine the lymphatic anatomy of the penis. He hypothesized that if penile carcinoma metastasized, it would do so to a node that was located medially and superiorly to the saphenofemoral junction in each groin (Cabanas, 1977). The term sentinel node, first coined by Gould in 1966 for parotid cancer (Gould et al., 1966), was used to describe the first node in this drainage pathway; if this was found to have metastatic disease, the patient required a lymphadenectomy. Conversely, when the SLN was negative for disease, the likelihood of metastatic disease in the groin was low and lymphadenectomy was unnecessary. The idea that a primary tumor would preferentially drain through the lymphatics to a specific lymph node, and that the status of that node would reflect the tumor status of the regional lymphatic basin, was revolutionary. However, the lymphatic drainage of solid tumors might vary from patient to patient and not necessarily be fixed to an anatomic location (Wong et al., 1991). To accurately identify the SLN, intraoperative techniques were needed to define the lymphatic drainage of a given primary tumor site rather than utilize an operative approach that was dependent upon the defined anatomy.

Thus, in 1992, Morton introduced the concept of identifying and selectively harvesting the SLN from the draining basin of a primary melanoma to identify patients with clinically occult lymph node disease (Morton et al., 1992). This was performed with intradermal 
injection of vital blue dye around the primary melanoma and then exploration of the regional lymphatic basin to identify blue stained node(s). This technique was based on the observation that when a blue dye such as isosulfan blue is injected around the primary melanoma, it drains into the SLN. With meticulous dissection, the dermal lymphatics could be visualized and utilized to map the lymphatic drainage of the skin to a SLN. In this study, metastases were present in $18 \%$ of SLNs, while non-sentinel nodes were the sole site of metastases in only two of 3079 nodes from 194 lymphadenectomy specimens that had an identifiable SLN, resulting in a false-negative (FN) rate of less than 1\% (Morton et al., 1992). Therefore, this technique identifies, with a high degree of accuracy, patients with early stage melanoma without nodal metastases who can be spared from a morbid radical lymphadenectomy. Several confirmatory studies, including prospective randomized trials, have provided a wealth of information regarding the SLN, including accuracy, prognostic value and candidate selection (Ross et al., 2011).

However, intraoperative lymphatic mapping with blue dye alone is technically difficult with prolonged learning curves to acquire satisfactory outcomes. Thus, radioguided techniques were sought to provide a simpler method to identify and harvest the SLN while minimizing the extent of the surgical dissection. In 1993, Alex and Krag reported on the use of an intra-operative hand-held gamma probe to identify regional nodes that had taken up technetium labeled sulfur colloid (Alex \& Krag, 1993). Additionally, the development of a number of radiopharmaceuticals with appropriate particle size provided the opportunity for the development of cutaneous lymphoscintigraphy, developed by Robinson, Morton and associates in the 1970s (Robinson et al., 1977). Cutaneous lymphoscintigraphy was especially important given the recognition that the dermal lymphatics, particularly in trunk melanomas (Leong et al., 1999), could have substantial variability; this allowed surgeons to define the regional lymphatic basins that were at risk for harboring metastatic disease prior to selective SLND (Fig. 2). Preoperative lymphoscintigraphy to define the SLN from the primary site in combination with the gamma probe could direct the surgical incisions and make the procedure less invasive than the blue dye procedure. Also, selective SLND using lymphoscintigraphy allows the identification of affected lymph nodes that would not be routinely evaluated during an elective nodal dissection such as in-transit lymph nodes and lymph nodes in minor nodal basins (e.g., popliteal and epitrochlear regions) [Sumner et al., 2002]. Lymphoscintigraphy is also essential for selective SLND in head and neck melanomas as these have complex and less predictable lymphatic drainage patterns, resulting in lower SLN identification rates and higher FN rates (Klop et al., 2011; Leong et al., 1999). For these reasons, cutaneous lymphoscintigraphy has become a routine component of the management of most melanoma patients.

\subsection{Accuracy and false-negative rate}

The SLN concept has been supported by high accuracy rates and low false-negative (FN) rates in melanoma. The immediate FN rate, defined as the percentage of nodal basins that harbor nodal metastases in nodes other than the SLN as determined by synchronous elective lymph node dissection after a negative SLN biopsy, has been reported to be less than $5 \%$ in several studies (Gershenwald et al., 1999; Morton et al., 1992; Nowecki et al., 2003, 2006; Reintgen et al., 1994; Thompson et al., 1995; Uren et al., 1994). In the Multicenter Selective Lymphadenectomy Trial I (MSLT-I) [Morton et al., 2006], 2,001 patients with cutaneous melanoma were randomized to: (1) wide local excision alone with observation only and subsequent lymphadenectomy if nodal relapse occurred, or (2) wide local excision and selective SLND with lymphadenectomy if metastases were found in the SLN. 


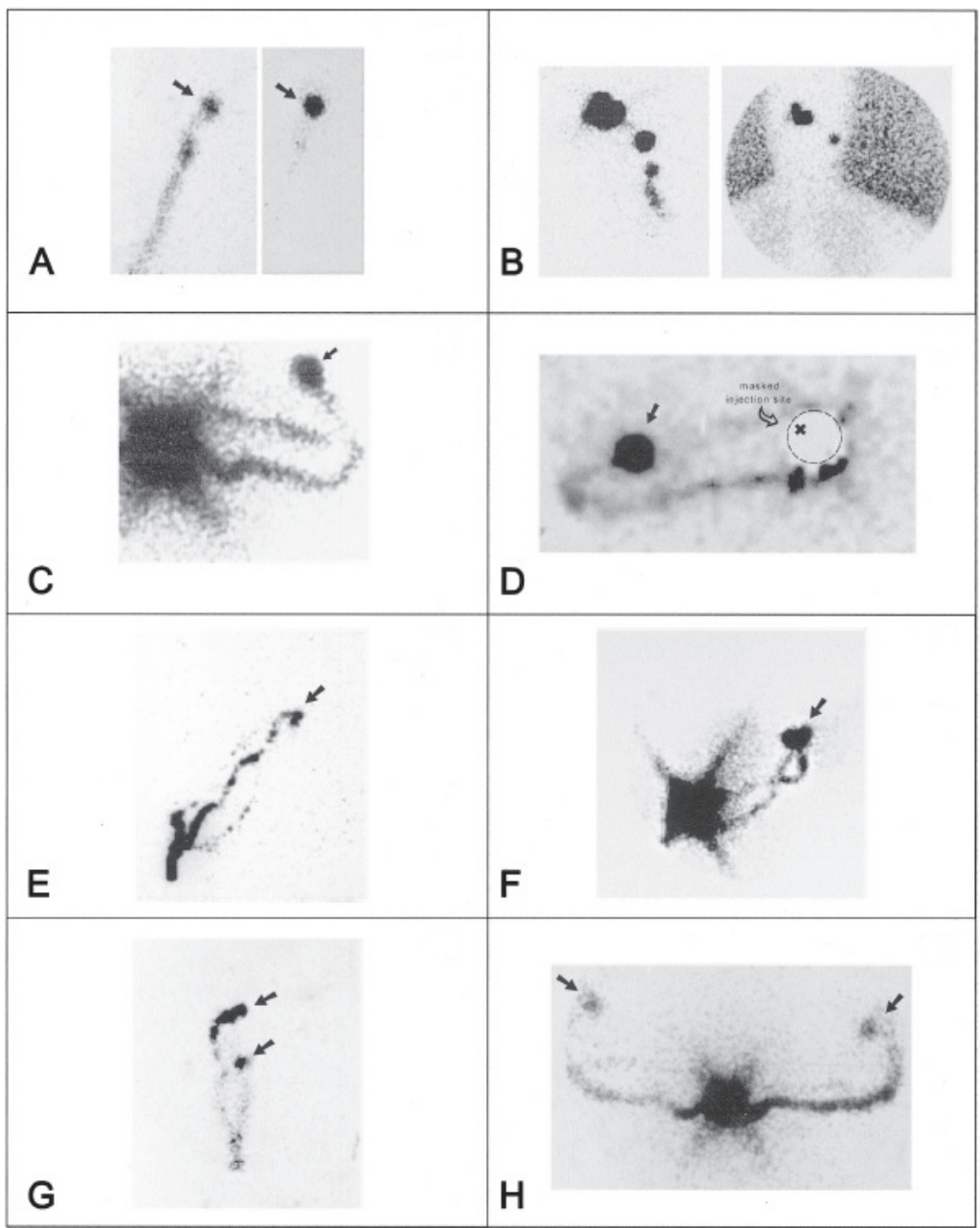

Fig. 2. Pre-operative lymphoscintigraphy demonstrates varying lymphatic channel patterns in patients with primary melanoma. (A) Drainage of a single channel from the right upper arm leading to one SLN in the right axilla. (B) Drainage of a single channel from a posterior midline neck lesion to multiple contiguous nodes in the right posterior neck. (C) Confluent channels drain from the upper back to a single SLN in the left axilla. (D) Multiple channels from the left upper back draining to a single SLN in the left axilla. (E) Single primary site drainage source from the right arm, diverting into several channels and leading to a single SLN in the right axilla. (F) Changing of drainage patterns from a lesion in the left anterior chest wall to one SLN in the left axilla. (G) Parallel simple channels from the right lower extremity, each draining to a single SLN, each in the same basin in the right groin. $(\mathrm{H})$ Multiple channels from the midline back draining to multiple SLN(s) in different basins, the right and left axilla. This figure has been previously published by our group in Clinical Nuclear Medicine 30(3):150-158, 2005. 
Results from 1,269 patients with intermediate-thickness primary melanoma (1.2 $\mathrm{mm}$ to 3.5 $\mathrm{mm}$ in this study) showed that $16 \%$ percent of SLNs had micrometastases, while $3.4 \%$ of those with "negative" SLNs developed nodal metastases, which is consistent with the accepted FN rates of the procedure.

Additional evidence that regional node metastasis constitutes an orderly, nonrandom event was provided from a study that examined 105 lymphadenectomy specimens in patients with at least one positive SLN (Gershenwald et al., 1998). They found that the SLN was the only node involved in 83 (79\%) of the basins, with microscopic nodal metastasis identified in an additional $21 \%$ of the lymphadenectomy specimens. In $92 \%$ of patients who had at least one positive SLN and were mapped with blue dye and radiocolloid, lymphatic metastases were identified in the SLN that contained the greatest radiotracer uptake.

\subsection{Current indications for selective SLND}

In our practice, patients chosen for selective SLND have the following: (1) a Breslow thickness of $1 \mathrm{~mm}$ or greater; (2) a Breslow thickness less than $1 \mathrm{~mm}$, but with high risk features such as lymphatic invasion, regression, ulceration, increased mitotic figures, or Clarks level IV; or (3) a shave biopsy that resulted in a Breslow thickness of less than $1 \mathrm{~mm}$. Patients who are not recommended to undergo selective SLND have one of the following features: (1) known lymphatic or metastatic disease; (2) melanoma-in-situ; or (3) a Breslow thickness less than $1 \mathrm{~mm}$ with no high risk features. These are the most current indications for selective SLND and what most melanoma centers follow. Given this criteria, the positive SLN rate has been documented to be between 14-21\% in most studies (Kapteijn et al., 1997; Leong et al., 2005; Morton et al., 1992, 2006; Thompson et al., 2005). Despite these guidelines, population based studies have shown that only $50 \%$ of patients with stage IB and II who met the criteria for selective SLND actually undergo selective SLND (Bilimoria et al., 2009; Cormier et al., 2005). The factors for this are likely multi-factorial including insurance, geographic area, socioeconomic factors, and age. This signifies the need for better education, access to health care, and melanoma multidisciplinary centers for patient referral.

\section{Technique and evaluation of SLN}

\subsection{Pre-operative lymphatic mapping}

The SLN is now reproducibly defined by lymphoscintigraphy and lymphatic mapping performed by the injection of Technetium-99m (Tc 99m) sulfur colloid radiotracer, a vital blue dye, or a combination of both around the melanoma site. Isosulfan blue (Lymphazurin $1 \%$, Hirsch Industries, Inc., Richmond, VA) is the most commonly used blue dye in the United States and is the only dye approved by the Food and Drug Administration for lymphatic mapping. Regarding radiotracer, a more selective agent, Technetium-99m-labeled Tilmanocept, is a mannose receptor-targeted molecule that is being developed for identification of SLNs (Leong et al., 2011) and will likely be used in the near future.

A summary of the numerous studies using the blue dye technique, radiotracer mapping by a hand-held gamma probe, or a combination of both techniques is shown in Table 1 . The success rate of harvesting the SLN by blue dye alone is less than that of radiotracer alone or the combination of blue dye and radiotracer, both of which now approach $100 \%$ (Table 1). Given this data, the use of radiotracer is the most commonly use technique now. With greater surgical experience, the use of blue dye is not essential as radiotracer has a higher 
sensitivity than blue dye alone and this can avoid reported allergic reactions seen with the injection of blue dye (Leong et al., 2000; Liu et al., 2011).

For this technique, filtered Tc99m sulfur colloid is injected intradermally at the primary melanoma site. Dynamic imaging is performed to follow the lymphatic collecting vessels until they reach the draining SLNs. An image should be acquired as the lymphatics reach the nodal basin so that SLN(s) directly receiving the channels can be identified and distinguished from any second tier nodes that may be seen. This phase of the study usually takes 10-20 minutes. Delayed scans are performed 2-2.5 hours later, at which time all regions that possibly drain the primary melanoma site are examined with 5-10 minute static images. The surface location of all $\operatorname{SLN}(\mathrm{s})$ is marked on the overlying skin. Close communication between the nuclear medicine physician and surgeon is invaluable, especially in cases where there are unusual draining patterns. Importantly, the SLN is not just the first node seen on dynamic imaging, since there may be multiple separate lymph channels that have different rates of lymph flow. If they drain to different nodes, these are all SLNs, regardless of the time taken for the lymph containing the radiocolloid to reach them (Fig. 2). The SLN is also not necessarily the closest node to the primary site. Lymphatic vessels can bypass many nodes and even whole node fields before reaching a SLN. Therefore, the best way to identify a SLN on lymphoscintigraphy is to see the lymphatic collecting vessel on dynamic imaging as it drains directly to the SLN (Fig. 2).

\begin{tabular}{|c|c|c|c|c|c|}
\hline Author & Year & \# of Patients & $\begin{array}{c}\text { Blue Dye } \\
\text { Alone }\end{array}$ & Radiotracer & Both \\
\hline Morton et al. & 1992 & 223 & $82 \%$ (basins) & - & - \\
\hline Krag et al. & 1995 & 121 & $\begin{array}{c}91 \% \\
\text { (patients) }\end{array}$ & $\begin{array}{c}98 \% \\
\text { (patients) }\end{array}$ & - \\
\hline Glass et al. & 1996 & 148 & $60 \%$ (nodes) & $80 \%$ (nodes) & $97 \%$ (nodes) \\
\hline Albertini et al. & 1996 & 106 & $70 \%$ (nodes) & $84 \%$ (nodes) & $96 \%$ (basins) \\
\hline Kapteijn et al. & 1997 & 110 & $84 \%$ (nodes) & $99.5 \%$ (nodes) & $99.5 \%$ (nodes) \\
\hline Leong et al. & 1997 & 163 & $74 \%$ & $98 \%$ & - \\
\hline Pijpers et al. & 1997 & 135 & $\begin{array}{c}86 \% \text { (nodes) } \\
85 \% \text { (basins) }\end{array}$ & $\begin{array}{c}100 \% \text { (nodes) } \\
100 \% \text { (basins) }\end{array}$ & - \\
\hline Gershenwald et al. & 1998 & 626 & $87 \%$ & - & $99 \%$ \\
\hline Gennari et al. & 2000 & 133 & $80.8 \%$ (nodes) & $97.1 \%$ & $99 \%$ \\
\hline Nowecki et al. & 2003 & 726 & $91.6 \%$ & - & $97.3 \%$ \\
\hline
\end{tabular}

* Reporting of success rates is not standardized. Percentages are indicated in patients, nodal basins or SLNs.

Table 1. Success Rates of Melanoma Sentinel Lymph Node Identification Techniques in Studies with >100 patients*.

\subsection{Intra-operative identification of the SLN(s)}

After lymphoscintigraphy, the patient is transferred to the operating room and no further injection of radiotracer is necessary, but Lymphazurin (1-2 $\mathrm{mL})$ may be injected intradermally prior to the procedure. The surgical sites are prepared and general anesthesia is most often used. Intraoperative mapping of the SLNs is achieved using a hand-held gamma probe (Neoprobe 2000, Neoprobe Corporation, Dublin, OH). A small incision is made over the marked area of greatest activity as detected by pre-operative lymphoscintigraphy and confirmed by the hand-held gamma probe. The incision is carried down through the subcutaneous fat and the fascia is incised as the lymph nodes usually 
reside beneath the fascia. Using the gamma probe, the SLNs can be located by detecting increased radioactivity in counts per second or blue dye within node. After the removal of the SLN, the gamma probe is used to search the resection bed to make sure that no residual elevated radioactivity remains. Theoretically, the single SLN with the highest radioactive count ("hottest" SLN) or the blue node is most likely to harbor tumor cells and is removed during biopsy. However, literature describes FN rates for SLN biopsy if only the single, "hottest" SLN is removed and the other nodes are left in place (McMasters et al., 2001). Thus, we and others use the 10\% rule (Liu et al., 2011; McMasters et al., 2001): the gamma probe is applied and any SLNs that assessed $\geq 10 \%$ of the ex vivo radioactive count of "hottest" SLN are removed, including any blue nodes or suspicious nodes by digital palpation.

After selective SLND, the wound is closed in layers. On a side table we dissect the SLN(s) from the non-SLN(s) or lymphatic tissue within the resected specimen using the gamma probe so that each lymph node is correctly labeled with its respective radioactive counts for pathologic evaluation.

\subsection{Pathologic assessment of the SLN}

The standard histological technique for evaluating a nodal dissection specimen involves evaluating representative sections from each identified lymph node using hematoxylin and eosin (H\&E). In actuality, given the large size of the nodal dissection specimen, $<1 \%$ of the whole specimen is routinely evaluated (Ross et al., 2011; Sondak et al., 2007). With a smaller sample from a selective SLND, the SLN can be evaluated more intensively with multiple sections using a combination of H\&E and immunohistochemistry (IHC) to stain for melanoma associated antigens such as S-100 and HMB-45 (Fig. 3).

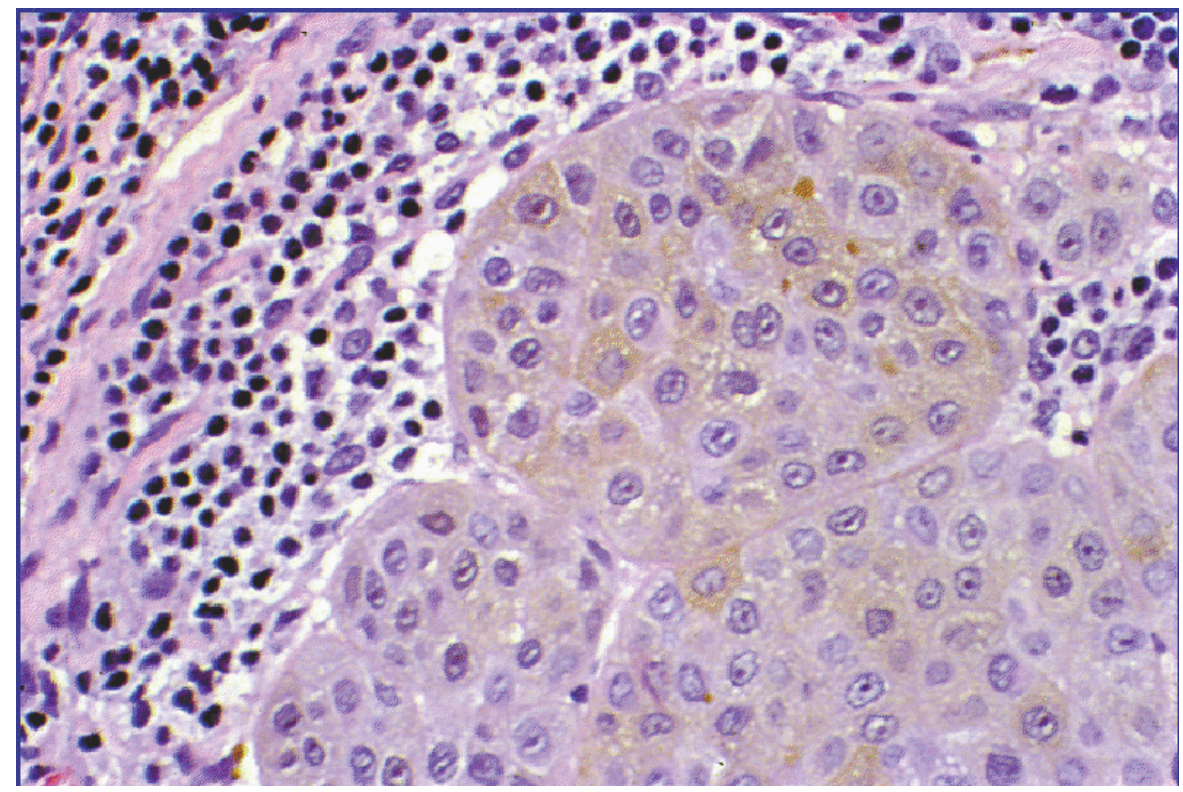

Fig. 3. Figure shows staining of melanoma micrometastasis within a SLN. 
Therefore, despite the less invasive nature of selective SLND, the staging data is likely more accurate than an elective lymph node dissection.

\section{Safety}

Selective SLND is a safe procedure with a very low complication rate. Additionally, the risk of radiation has been studied in physicians injecting the radiotracer as well as the surgeons removing the nodes. The maximum recorded dose of radiation recorded was 1900 times smaller than the current 1 year dose limit recommended by the International Commission on Radiological Protection, and no limitations are needed in the number of surgical interventions performed yearly (Nejc et al., 2006; Sera et al, 2003).

There have been reports of adverse allergic reactions to blue dye (Leong et al., 2000) which can range from a mild allergic reaction to anaphylaxis associated with hypotension, pulmonary edema, and/or cardiovascular collapse. It is hypothesized that prior exposure to common household products is responsible for patient sensitization to blue dye. Single institution case studies quote allergic reaction rates of 0.7 to $2 \%$ for melanoma. A multiinstitutional survey by our group of 14,800 melanoma patients treated with blue dye in over 185 institutions revealed a $0.4 \%$ rate of adverse blue dye reactions, most of which are mild. Despite this low rate, it is important to be aware of any adverse reactions such as urticaria, respiratory and hemodynamic changes which usually occur in the first 10 to 20 minutes. We recommend that the anesthesiologist and nursing team are made aware of the use of blue dye prior to its injection, an intravenous line always be inserted, and that the proper medications, including epinephrine and corticosteroids, be readily available. If blue dye is to be used, we suggest that the surgeon use as little blue dye as needed; we have found reliable results in head and neck melanoma using less than 1 cc per injection. Additionally, blue dye is not essential as we demonstrated in a recent study that using the $10 \%$ radioactivity rule (McMasters et al., 2001) with blue dye does not significantly decrease the Miss Rate when compared to the $10 \%$ radioactivity rule with technitium alone (Liu et al., 2011).

\section{Clinical relevance of sentinel lymph node}

Further support for the SLN concept stems from research that clearly shows that SLN status is the most significant prognostic factor with respect to disease-free and overall survival as shown in Table 2. Selective SLND is an excellent staging technique and can be used to identify patients who would or would not benefit from a complete lymphadenectomy and is also necessary for inclusion in clinical trials.

\subsection{Positive node}

As shown in Table 2, patients with a positive SLN have a significantly decreased overall 5year survival compared to patients with a negative SLN. Therefore, for patients with a positive SLN, therapeutic decisions should be made and most often a regional lymphadenectomy is recommended. However, the survival benefit of selective SLND followed by completion lymph node dissection (CLND) is still controversial and many groups have attempted to study this by comparing melanoma patients after CLND after positive sentinel node biopsy and after therapeutic lymph node dissection for clinically detected regional lymph node metastases. In the MSLT-1 trial (Morton et al., 2006), among patients with nodal metastases (primary melanomas ranging from 1.2 to $3.5 \mathrm{~mm}$ ), the 5-year 
melanoma specific survival rate of those who underwent selective SLND with immediate lymphadenectomy $(72.3 \%)$ for a positive SLN was significantly higher than those in the observation group who had lymphadenectomy only when there was clinically evident nodal disease $(52.4 \% ; p=.004)$. However, no overall survival advantage was seen when comparing the entire cohort of patients randomized to selective SLND with those patients who had wide excision only and nodal observation. Other data from meta-analysis of 6 studies showed a significantly higher risk of death for patients who only underwent elective lymph node dissection after clinically evident nodal metastasis versus patients who underwent SLN-guided CLND (Pasquali et al., 2010). However, this is a complex topic and survival benefit is also likely related to other factors including age, primary tumor characteristics, and features of the nodal metastases. Additionally, these studies tend to be underpowered because of a low percentage of patients with positive SLN(s) who could potentially benefit from CLND (Ross et al., 2011).

\subsection{Negative node}

When SLNs are negative for micrometastasis, the remainder of the lymph node basin is usually negative (Morton et al., 1992; Reintgen et al., 1994; Albertini et al., 1996; Krag et al., 1995; Ross et al., 1993; Thompson et al., 1994) with FN rates under 5\%. This is good evidence to conclude that melanoma metastases are most often spread in an orderly pattern (Fig.1). In general, if the SLNs are negative, there is no need to proceed with a more morbid regional lymph node dissection; selective SLN mapping replaces the more extensive lymph node dissection if SLNs are found to contain no metastasis.

Patients with a negative SLN have an overall 5 year survival of 84 to 92\%, significantly better than positive node patients. Despite better survival results, a negative SLN is not an absolute predictor of survival. Recurrence and death in SLN negative patients may be related to FN SLN results or a pure hematogenous spread (Leong et al., 2004, 2011; Ross et al., 2011). In particular, head and neck melanomas have a higher FN rate, over $12 \%$ in some studies (Klop et al., 2011); this is likely due to a complex lymphatic drainage pattern with multiple basins in the head and neck (Leong, 2011). FN results for selective SLND may result from failed preoperative lymphoscintigraphy, including injection techniques and interpretation of the lymphoscintigraphy, failed intraoperative lymphatic mapping, failed pathologic identification of microscopic disease, and "skip" metastasis (Leong, 2004). Predictors of relapse and death in SLN negative patients include increasing tumor thickness and ulceration (Ross et al., 2011).

\begin{tabular}{|c|c|c|c|c|c|}
\hline \multirow{2}{*}{ Author } & \multirow{2}{*}{ Year } & \multirow{2}{*}{$\begin{array}{c}\text { \# of } \\
\text { Patients }\end{array}$} & \multicolumn{2}{|c|}{ 5-Year Overall Survival } & \multirow{2}{*}{$p$-value } \\
\hline & & & Negative Node & Positive Node & \\
\hline Nowecki ZI & 2003 & 726 & $84 \%$ & $40 \%$ & $<0.001$ \\
\hline Leong SP & 2005 & 363 & $85.6 \%$ & $61.5 \%$ & $<0.0001$ \\
\hline Morton DL & 2006 & 1269 & $90 \%$ & $72 \%$ & $<0.001$ \\
\hline Cascinelli $\mathrm{N}$ & 2006 & 1108 & $90.6 \%$ & $75.4 \%$ & $<0.0001$ \\
\hline Mandalà M & 2009 & 1251 & $88.7 \%$ & $42.9 \%$ & $<.0001$ \\
\hline Kunter C & 2010 & 1049 & $90 \%$ & $58 \%$ & $<0.001$ \\
\hline Ellis MC & 2010 & 397 & $92 \%$ & $73 \%$ & 0.0001 \\
\hline
\end{tabular}

Table 2. Overall Survival in Relation To Sentinel Lymph Node Status. 


\section{Biology and clinical impact of micrometastasis in SLN(s)}

The dimensions and "amount" of micrometastasis in the SLN gives important prognostic data. According to the Rotterdam criteria for SLN tumor burden (van Akkooi et al., 2006, 2008), the maximum diameter of the largest focus of a positive $\operatorname{SLN}(\mathrm{s})$ is used as the measurement of record. There were 388 melanoma patients with positive SLNs from three European centers analyzed by this method with a median follow-up of 36 months. Three groups of patients were defined: (1) submicrometastasis with at least 10 cells but less than $0.1 \mathrm{~mm}(10 \%)$; (2) micrometastasis between 0.1 and $1.0 \mathrm{~mm} \mathrm{(35 \% );} \mathrm{and} \mathrm{(3)} \mathrm{micrometastasis}$ greater than $1.0 \mathrm{~mm}(55 \%)$. Patients with sub-micrometastasis $(<0.1 \mathrm{~mm})$ were identical to the SLN-negative group with an excellent survival rate. Tumor burden in SLNs increased with T-stage. Both T4 and SLN tumor burden were the most important factors for overall survival.

Similarly, 63 melanoma patients with positive SLNs from the UCSF melanoma SLN database with a median follow-up of 8 years were analyzed (Baehner et al., 2011). SLN micrometastasis was recorded for size, number of foci and anatomic location by H\&E. Fourteen of 63 patients had positive non-SLNs. Using the log-rank test, maximum metastatic size and primary melanoma thickness were correlated with progression-free survival and overall survival. Neither number of metastatic foci nor microscopic location was statistically significant. Multivariate analysis showed that the maximum metastatic size and primary melanoma thickness were the most important prognostic factors for progression-free survival and overall survival. As a continuous variable, every $5.0 \mathrm{~mm}$ increase in maximum metastatic size was predictive of progression-free survival. The estimated 5-year overall survival rate was $90 \%$ in patients with maximum metastatic size $<0.6 \mathrm{~mm}, 52 \%$ with maximum metastatic size from 0.6 to $5.5 \mathrm{~mm}$, and $55 \%$ with maximum metastatic size $>5.5$ $\mathrm{mm}$. When stratified by thickness, the estimated 5 -year progression-free survival rates were $95 \%$ for patients with maximum metastatic size $<1.6 \mathrm{~mm}, 70 \%$ between 1.6 and $4.5 \mathrm{~mm}$, and $45 \%>4.5 \mathrm{~mm}$; the overall survival were $82 \%, 52 \%$, and $5 \%$. Both primary melanoma thickness and maximum metastatic size were independently prognostic of progression-free survival and overall survival in melanoma patients (Baehner et al., 2011). Other studies have also demonstrated that the incidence of SLN metastases correlates directly

with increasing tumor thickness (Gershenwald et al., 1998; Ross, 2011) as well as other factors including ulceration, lymphatic invasion, mitotic rate, Clark level, and anatomic site (Ross, 2011).

\section{Conclusion}

The overall challenge in melanoma is to identify patients with truly localized disease versus patients with metastasis to nodal and/or systemic sites, as early detection remains key to successful eradication. With this in mind, selective SLND was introduced 20 years ago and has become essential in the care of patients with cutaneous melanoma, with a multitude of publications validating the importance of the SLN. Selective SLND provides a minimally invasive standard of care (Morton et al, 2008), that allows accurate staging, gives significant prognostic information, facilitates therapeutic lymphadenectomy with regional disease control, avoids unnecessary elective lymph node dissection, and may improve survival in node-positive patients. However, in a minority situations ( $20 \%$ of the time), cancer cells may spread through the vascular system to distant sites, bypassing the SLNs (Leong et al., 
2011). Therefore, it is important that all patients with melanoma be followed closely after their diagnosis.

\section{References}

Albertini, J.J., Cruse, C.W., Rapaport, D., Wells, K., Ross, M., DeConti, R., Berman, C.G., Jared, K., Messina, J., Lyman, G., Glass, F., Fenske, N. \& Reintgen, DS. (1996). Intraoperative radiolymphoscintigraphy improves sentinel lymph node identification for patients with melanoma. Ann Surg, 223(2):217-224.

Alex, J.C. \& Krag, D.N. (1993). Gamma-probe guided localization of lymph nodes. Surg Oncol, 2(3):137-143.

Baas, P.C., Schraffordt Koops, H., Hoekstra, H.J., van Bruggen, J.J., van der Weele, L.T. \& Oldhoff, J. (1992). Groin dissection in the treatment of lower-extremity melanoma. Short term and long-term morbidity. Arch Surg, 127(3):281-286.

Baehner, F., Jenkins, T., Hwang, J. \& Leong, S.P.L. (2011). Impact of microscopic tumor burden in sentinel lymph nodes on the outcome of melanoma patients. Submitted for publication.

Baldwin, B.T, Cherpelis, B.S., Sondak, V. \& Fenske, N.A. (2010). Sentinel lymph node biopsy in melanoma: Facts and controversies. Clin Dermatol, 28(3):319-323.

Balch, C.M., Morton, D.L., Gershenwald, J.E., McMasters, K.M., Nieweg, O.E., Powell, B., Ross, M.I., Sondak, V.K. \& Thompson, J.F. (2009). Sentinel node biopsy and standard of care for melanoma. J Am Acad Dermatol, 60(5):872-875.

Bilimoria, K.Y., Balch, C.M., Wayne, J.D., Chang, D.C., Palis, B.E., Dy, S.M. \& Lange, J.R. (2009). Health care system and socioeconomic factors associated with variance in use of sentinel lymph node biopsy for melanoma in the United States. J Clin Oncol, 27(11):1857-1863.

Cabanas, R.M. (1977). An approach for the treatment of penile carcinoma. Cancer, 39(2):456466.

Cormier, J.N., Xing, Y., Ding, M., Lee, J.E., Mansfield, P.F., Gershenwald, J.E., Ross, M.I. \& $\mathrm{Du}$, X.L. (2005). Population-based assessment of surgical treatment trends for patients with melanoma in the era of sentinel lymph node biopsy. J Clin Oncol, 23(25):6054-62.

Ellis, M.C., Weerasinghe, R., Corless, C.L. \& Vetto, J.T. (2010). Sentinel lymph node staging of cutaneous melanoma: predictors and outcomes. Am J Surg, 199(5):663-668.

Glass, L.F., Messina, J.L., Cruse, W., Wells, K., Rapaport, D., Miliotes, G., Berman, C., Reintgen, D. \& Fenske, N.A. (1996). The use of intraoperative radiolymphoscintigraphy for sentinel node biopsy in patients with malignant melanoma. Dermatol Surg, 22(8):715-270.

Gennari, R., Bartolomei, M., Testori, A., Zurrida, S., Stoldt, H.S., Audisio, R.A., Geraghty, J.G., Paganelli, G. \& Veronesi, U. (2000). Sentinel node localization in primary melanoma: preoperative dynamic lymphoscintigraphy, intraoperative gamma probe, and vital dye guidance. Surgery, 127(1):19-25.

Gershenwald, J.E., Tseng, C.H., Thompson, W., Mansfield, P.F., Lee, J.E., Bouvet, M., Lee, J.J. \& Ross, M.I. (1998). Improved sentinel lymph node localization in patients with primary melanoma with the use of radiolabeled colloid. Surgery, 124(2):203-1

Gershenwald, J.E., Thompson, W., Mansfield, P.F., Lee, J.E., Colome, M.I., Tseng, C.H., Lee, J.J., Balch, C.M., Reintgen, D.S. \& Ross, M.I. (1999). Multi-institutional melanoma 
lymphatic mapping experience: The prognostic value of sentinel lymph node status in 612 stage I and II melanoma patients. J Clin Oncol, 17(3):976-983.

Gould, E.A., Winship, T., Philbin, P.H. \& Kerr, H.H. (1960). Observations on a "sentinel node" in cancer of the parotid. Cancer, 13:77-78.

Hellman, S. (1994) Natural history of small breast cancers. JCO Karnofsky Memorial Lecture $12,2229-2234$.

Kapteijn, B.A, Nieweg, O.E., Liem, I., Mooi, W.J., Balm, A.J., Muller, S.H., Peterse, J.L., Valdés Olmos, R.A., Hoefnagel, C.A. \& Kroon, B.B. (1997). Localizing the sentinel node in cutaneous melanoma: gamma probe detection versus blue dye. Ann Surg Oncol, 4(2):156-160.

Klop, W.M., Veenstra, H.J., Vermeeren, L., Nieweg, O.E., Balm, A.J. \& Lohuis, P.J. (2011). Assessment of lymphatic drainage patterns and implications for the extent of neck dissection in head and neck melanoma patients. J Surg Oncol, Jan 31.

Leong, S.P., Achtem, T.A., Habib, F.A., Steinmetz, I., Morita, E., Allen, R.E., Kashani-Sabet, M. \& Sagebiel, R. (1999). Discordancy between clinical predictions vs lymphoscintigraphic and intraoperative mapping of sentinel lymph node drainage of primary melanoma. Arch Dermatol, 135(12):1472-1476.

Leong, S.P., Donegan, E., Heffernon, W., Dean, S. \& Katz, J.A. (2000). Adverse reactions to isosulfan blue during selective sentinel lymph node dissection in melanoma. Ann Surg Oncol, 7(5):361-6

Leong, S.P. (2004), Sentinel lymph node mapping and selective lymphadenectomy: the standard of care for melanoma. Curr Treat Options Oncol, 5(3):185-194

Leong, S.P., Kashani-Sabet, M., Desmond, R.A., Kim, R.P., Nguyen, D.H., Iwanaga, K., Treseler, P.A., Allen, R.E. Jr, Morita, E.T., Zhang, Y., Sagebiel, R.W. \& Soong, S.J. (2005). Clinical significance of occult metastatic melanoma in sentinel lymph nodes and other high-risk factors based on long-term follow-up. World J Surg, 29(6):683691.

Leong, S.P., Kim, J., Ross, M., Faries, M., Scoggins, C.R., Rich Metz, W.L., Cope, F.O. \& Orahood, R.C. (2011). A Phase 2 Study of 99mTc-Tilmanocept in the Detection of Sentinel Lymph Nodes in Melanoma and Breast Cancer. Ann Surg Oncol, 18:961969.

Leong, S.P. (2011). Role of selective sentinel lymph node dissection in head and neck melanoma. J Surg Oncol, in press.

Leong, S.P., Zuber, M., Ferris, R.L., et al. (2011). Impact of nodal status and tumor burden in sentinel lymph nodes on the clinical outcomes of cancer patients. J Surg Oncol, in press.

Liu, L.C., Parrett, B.M., Jenkins, T., et al. (2011). Selective Sentinel Lymph Node Dissection for Melanoma: Importance of Harvesting Nodes with Lower Radioactive Counts without the Need for Blue Dye. Ann Surg Oncol, in press.

McMasters, K.M., Reintgen, D.S., Ross, M.I., Wong, S.L., Gershenwald, J.E., Krag, D.N., Noyes, R.D., Viar, V., Cerrito, P.B. \& Edwards, M.J. (2001). Sentinel Lymph Node Biopsy for Melanoma: How Many Radioactive Nodes Should Be Removed? Ann Surg Oncol, 8(3):192-197.

Morton, D.L., Wen, D.R., Wong, J.H., Economou ,J.S., Cagle, L.A., Storm, F.K., Foshag, L.J. \& Cochran, A.J. (1992). Technical details of intraoperative lymphatic mapping for early stage melanoma. Arch Surg, 127(4):392-399. 
Morton, D.L., Thompson, J.F., Essner, R., Elashoff, R., Stern, S.L., Nieweg, O.E., Roses, D.F., Karakousis, C.P., Mozzillo, N., Reintgen, D., Wang, H.J., Glass, E.C. \& Cochran, A.J. (1999). Validation of the accuracy of intraoperative lymphatic mapping and sentinel lymphadenectomy for earlystage melanoma: a multicenter trial. Multicenter Selective Lymphadenectomy Trial Group. Ann Surg, 230(4):453-463.

Morton, D.L., Thompson, J.F., Cochran, A.J., Mozzillo, N., Elashoff, R., Essner, R., Nieweg, O.E., Roses, D.F., Hoekstra, H.J., Karakousis, C.P., Reintgen, D.S., Coventry, B.J., Glass, E.C. \& Wang, H.J.; MSLT Group. (2006). Sentinel-node biopsy or nodal observation in melanoma. N Engl J Med, 355(13):1307-1317.

Morton, D.L., Cochran, A.J. \& Thompson, J.F. (2008). The rationale for sentinel-node biopsy in primary melanoma. Nat Clin Pract Oncol, 5(9):510-511.

Nejc, D., Wrzesień, M., Piekarski, J., Olszewski, J., Pluta, P., Kuśmierek, J. \& Jeziorski, A. (2006). Sentinel node biopsy in skin melanoma patients--measurements of absorbed doses of radiation to the hands of medical staff. J Surg Oncol, 93(5):355-361.

Nowecki, Z.I., Rutkowski, P., Nasierowska-Guttmejer, A. \& Ruka, W. (2003). Sentinel lymph node biopsy in melanoma patients with clinically negative regional lymph nodes-one institution's experience. Melanoma Res, 13(1):35-43.

Pasquali, S., Mocellin, S., Campana, L.G., Bonandini, E., Montesco, M.C., Tregnaghi, A., Del Fiore, P., Nitti, D. \& Rossi, C.R. (2010). Early (sentinel lymph node biopsy-guided) versus delayed lymphadenectomy in melanoma patients with lymph node metastases : personal experience and literature meta-analysis. Cancer, 116(5):12011209.

Reintgen, D., Cruse, C.W., Wells, K., Berman, C., Fenske, N., Glass, F., Schroer, K., Heller, R., Ross, M. \& Lyman, G. (1994). The orderly progression of melanoma nodal metastases. Ann Surg, 220(6):759-767.

Robinson, D.S., Sample, W.F., Fee, H.J., Holmes, C. \& Morton, D.L. (1977). Regional lymphatic drainage in primary malignant melanoma of the trunk determined by colloidal gold scanning. Surg Forum, 28:147-148.

Ross, M.I., Thompson, J.F. \& Gershenwald, J.E. (2011) Sentinel lymph node biopsy for melanoma: critical assessment at its twentieth anniversary. Surg Oncol Clin N Am, 20:57-78.

Sera, T., Mohos, G., Papos, M., Osvay, M., Varga, J., Lazar, M., Kiss, E., Kapitany, K., Dobozy, A., Csernay, L. \& Pavics, L. (2003). Sentinel node detection in malignant melanoma patients: radiation safety considerations. Dermatol Surg, 29(2):141-145.

Sondak, V.K., Zager, J.S. \& Messina, J.L. (2007). Sentinel lymph node biopsy as the standard of care for cutaneous melanoma. Clin Adv Hematol Oncol, 5(6):483-490.

Stebbins, W.G., Garibyan, L. \& Sober, A.J. (2010). Sentinel lymph node biopsy and melanoma: 2010 update Part I. J Am Acad Dermatol, 62(5):723-734.

Sumner, W.E. 3rd, Ross, M.I., Mansfield, P.F., Lee, J.E., Prieto, V.G., Schacherer, C.W. \& Gershenwald, J.E. (2002). Implications of lymphatic drainage to unusual sentinel lymph node sites in patients with primary cutaneous melanoma. Cancer, 95(2):354360 .

Thompson, J.F., McCarthy, W.H., Bosch, C.M.J., O'Brien, C.J., Quinn, M.J., Paramaesvaran, S., Crotty, K., McCarthy, S.W., Uren, R.F. \& Howman-Giles, R. (1995). Sentinel lymph node status as an indicator of the presence of metastatic melanoma in regional lymph nodes. Melanoma Res, 5(4):255-260. 
Uren, R.F., Howman-Giles, R., Thompson, J.F., Shaw, H.M., Quinn, M.J., O'Brien, C.J., McCarthy, W.H. (1994). Lymphoscintigraphy to identify sentinel lymph nodes in patients with melanoma. Melanoma Res, 4(6):395-399.

van Akkooi, A., de Wilt, J., Verhoef, C., Schäfer-Hesterberg, G., Michej, W., de Wilt, J.H., Rutkowski P, Verhoef, C. \& Eggermont, A.M. (2006) Clinical relevance of melanoma micrometastases $(<0.1 \mathrm{~mm})$ in sentinel nodes: Are these nodes to be considered negative? Ann Oncol, 17:1578-1585.

van Akkooi, A.C., Nowecki, Z.I., Voit, C., Schäfer-Hesterberg, G., Michej, W., de Wilt, J.H., Rutkowski, P., Verhoef, C. \& Eggermont, A.M. (2008) Sentinel node tumor burden according to the Rotterdam criteria is the most important prognostic factor for survival in melanoma patients: A multicenter study in 388 patients with positive sentinel nodes. Ann Surg, 248(6):949-955.

Wong, J.H., Cagle, L.A. \& Morton, D.L. (1991). Lymphatic drainage of skin to a sentinel lymph node in a feline model. Ann Surg, 214(5):637-641.

Wrightson, W.R., Wong, S.L., Edwards, M.J., Chao, C., Reintgen, D.S., Ross, M.I., Noyes, R.D., Viar, V., Cerrito, P.B. \& McMasters, K.M.; Sunbelt Melanoma Trial Study Group. (2003). Complications associated with sentinel lymph node biopsy for melanoma. Ann Surg Oncol, 10(6):676-680. 


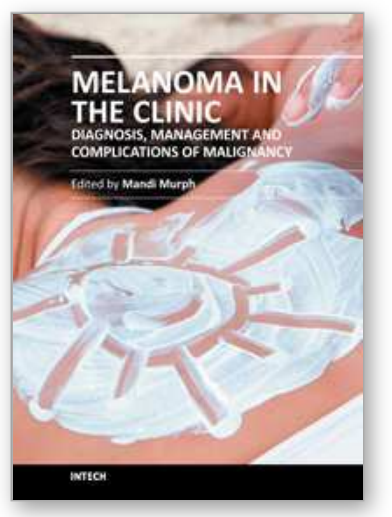

\section{Melanoma in the Clinic - Diagnosis, Management and Complications of Malignancy}

Edited by Prof. Mandi Murph

ISBN 978-953-307-571-6

Hard cover, 310 pages

Publisher InTech

Published online 23, August, 2011

Published in print edition August, 2011

This book provides an excellent overview of how melanoma is treated in the clinic. Since oncologists and clinicians across the globe contributed to this book, each area also explores the unique burdens that geographical areas experience from melanoma subtypes and how these are treated in different settings. It also includes several chapters that illustrate novel methods for diagnosing melanoma in the clinic using new technologies, which are likely to significantly improve outcomes. Several chapters cover surgical techniques and other present very rare or challenging clinical cases of melanoma and how these were treated. The book is geared towards informing clinicians and even patients how melanoma arises, what tools are available and which decisions need to be made by patients and their families in order to treat this devastating disease.

\section{How to reference}

In order to correctly reference this scholarly work, feel free to copy and paste the following:

Brian Parrett, Lilly Fadaki, Jennifer Y. Rhee and Stanley P.L. Leong (2011). The Biology and Clinical Relevance of Sentinel Lymph Nodes in Melanoma, Melanoma in the Clinic - Diagnosis, Management and Complications of Malignancy, Prof. Mandi Murph (Ed.), ISBN: 978-953-307-571-6, InTech, Available from: http://www.intechopen.com/books/melanoma-in-the-clinic-diagnosis-management-and-complications-ofmalignancy/the-biology-and-clinical-relevance-of-sentinel-lymph-nodes-in-melanoma

\section{INTECH}

open science | open minds

\author{
InTech Europe \\ University Campus STeP Ri \\ Slavka Krautzeka 83/A \\ 51000 Rijeka, Croatia \\ Phone: +385 (51) 770447 \\ Fax: +385 (51) 686166 \\ www.intechopen.com
}

\author{
InTech China \\ Unit 405, Office Block, Hotel Equatorial Shanghai \\ No.65, Yan An Road (West), Shanghai, 200040, China \\ 中国上海市延安西路65号上海国际贵都大饭店办公楼 405 单元 \\ Phone: +86-21-62489820 \\ Fax: +86-21-62489821
}


(C) 2011 The Author(s). Licensee IntechOpen. This chapter is distributed under the terms of the Creative Commons Attribution-NonCommercialShareAlike-3.0 License, which permits use, distribution and reproduction for non-commercial purposes, provided the original is properly cited and derivative works building on this content are distributed under the same license. 